\title{
The effect of the binary space and social interaction in creating an actual context of understanding the traditional urban space
} ${ }^{*}$ Ph. D. Candidate MUSTAFA AZIZ MOHAMMAD AMEN ${ }^{*}$, Dr. DUSKO KUZOVIC ${ }^{2}$

${ }^{1}$ Cihan University, Kurdistan, Iraq

${ }^{2}$ University of East Sarajevo, Bosnia and Herzegovina

E mail: mustafaamen@gmail.com E mail: dusko.kuzovic@gmail.com

\begin{tabular}{l}
\hline A R T I C L E I N F O: \\
\hline Article history: \\
Received 2 August 2017 \\
Accepted 11December 2017 \\
Available online 16December \\
2017 \\
\hline Keywords: \\
Urban Space; \\
Traditional city; \\
Prototypes; \\
Context; \\
Synchronic; \\
Diachronic. \\
\hline
\end{tabular}

This work is licensed under a Creative Commons Attribution - NonCommercial - NoDerivs 4.0. "CC-BY-NC-ND"

\section{A B S T R A C T}

Urban Space is not just a simple, physical configuration. Instead, it is a transformation of human experiences with the differentsynchronicarchitectural characteristic that needs a critical examination to segregate discrete layers of structural elements. As a result, the traditional urban space is a unique existence of reality; it is a product of prolonged interaction between society and architecture. The association is so prevailing that each portion has a significant role in creating a combination of mental prototypes of interpretation between the different factors that gives the urban space its final form. Neglecting any part in the public space perception process is leading to crash the binary equation letting the meaning paralyzed without being able to represent any society or potentially keep the sense. There are many examples of worn-out urban space some of them was a result of ignorance and absent of realization of the interaction between Society and architecture. Al-Kadhimiya, a city north of Baghdad, the capital of Iraq, is a crucial example of this type. The Iraqi municipality demolished that relationship by importing different layers that are not compatible with the original one or as a result of inserting new means of technology in the heart of the historic cities. The other example from Erbil, a city north of Iraq, where the municipality determinable removed the old fabric to insert a well-defined rectangle space, somehow to create an urban public space, that procedure juxtaposed by form a barrier to isolate the old Souk from the other part of the old city. Both cities suffered from a misunderstanding of the urban binary equation between space and architecture as a tool to understand the context.

Journal Of CONTEMPORARY URBAN AFFAIRS (2018) 2(2), 71-77.

https://doi.org/10.25034/ijcua.2018.3672

WwW.ijcua.com

Copyright (C) 2017 Journal Of Contemporary Urban Affairs. All rights reserved.

\section{Introduction}

There are many ways for communication, but the spaces is the interactive one. According to Lawson the very phrase 'face to face' is implicitly refers to space(Lawson,2001). There is a hidden language between the different part of the societies, the urban space as a component of the urban fabric plays its role in that language as a Part of the whole, the part has a phenomenological dimension in addition to its relational structure with the system as a whole.

*Corresponding Author:

Cihan University, Kurdistan, Iraq

E-mail address: mustafaamen@gmail.com 
Social science support that the "'personal space' and 'human territoriality' also tie space to the human agent, and do not acknowledge its existence independently of the human agent.

\section{Communication through urban fabric}

Harold Proshansky said, "The physical environment that we construct is as much a social phenomenony (Lawson, 2001). If any urban fabric has its internal system, then those "descriptions of space can be related both to the everyday buildings that make up the system and to the various»)(Hlillier \&Hanson, 2009) kinds of public building that exist within the urban fabric. Space is medium for interaction understanding as well as understand the message behind the urban fabric. There are different layers of combinations to transfer the meaning or as a way of shifting the meaning. In another word, there is continuous changes and modifications in the fabric from diachronic point view. So, there is a need to understand the underlying structure which regulates the spaces within the entire urban fabric. For Space gets its meaning through its direct connections with human consciousness.

\section{Society and Urban Fabrics binary interaction. 3.1 Introduction}

Both Space and Society have a particular structure which is modified and molded in almost complete compatibility with the other with all its intrinsic values. The understanding of the reality through a binary interaction and understand the meaning of the context, text, and urban fabric is a vast field, its root goes back to some other artistic field. In linguistics, Saussure insisted uthat our ability to discern phonemic structures requires that we recognize units of meaning such that they are reiterable..) (Winters, 2007). Saussure did not consider it necessary to distinguish between a language where that consists in the mastery of concepts and grasping content on the one hand and investing insight with connotation on the other.

\subsection{Structuralism binary interpretation.}

In its simplest form, structuralism is an analytical approach to consider phenomena as a complex system of variables operating under the certain universal rule. The urban space plays a significant role in understanding the essential meaning of any urban fabric. The undistinguishable world comprises of the structures that inspire and establish all of these phenomena is the underlying phenomena, which is "consists of the structures that underlie and organize all of these phenomena so that wecan make sense of them.» (Tyson, 2006). The first one related to the physical world. Architecture and urban design are similar to the internal relationships between the different spaces and architectural masses to create some pattern or order or Deep Structure (Hlillier \&Hanson, 2009).Although the meaning has a structure, that meaning is not alone and related to different layers with a different period. As a result, there are different layers of structures that stacked above each other, the combination of those layers composes the final sign of the urban form

\subsection{Phenomenological view}

Phenomenology role is to probe for the deeper structure of human reality and thereby to articulate the "language of metaphors that can be identified with our existence.) (Hlillier \&Hanson, 2009) Phenomenology further emphasizes the fact that architecture is first and foremost a multi-sensory experience as opposed to a purely visual or conceptual exercise. There is a focus on the human place uthe structure of place becomes manifest as environmental totalities which comprise the aspects of character and space.ll (Schulz, 1991). The theory focused on experiences and its interpretation by a human. It is crucial to get that the skills play a prominent role in understanding the space, but then what remains is how to transfer those feeling or experience accordingly. This method is well determined and identified for a single area where spectator could record his own experiences, but the question remained about the relationship of that space with the other related spaces! How could be so sure about the interconnection with other spaces? Although the phenomenological offer a useful tool to recognize places and its internal structures, it is suffering from indications that connect spaces with each other. It is worth to say that the Structuralists offer a better method for understanding the connection between the elements.

\subsection{Post-Structuralism and Deconstructionism approach.}

The post-structuralism focused on time and Changing of the meaning accordingly 
there is no fixed connection between the signifiers and the signified or between the urban fabric or space as well as the context with interpretationbeing created by the subconscious or the spectator so it

Sought to redress the universalizing tendencies of structuralism by introducing a particular specificity into the discourse. Thus against the static and universal models of structuralism, post-structuralism introduced notions of time and difference (Leach, 1997).

In its most exciting form, deconstruction saw as a way of undermining "all statements about the world, leaving us both silent and stricken with the acute condition of undesirability a fatal malady in most academic and political circles.n (Mallgrave \& Goodman, 2011). The instability of the meaning is the purpose coherent in the post and deconstruction it leads to «emphasize the aspect of a difference it which is differentiation over that which is a deferral..l (Massey, 2008). Here we have the concept of (Time/Space) as a tool to affect the different structures of the meaning accordingly. The research believes that the understanding of the final meaning through various layers is more reliable and acceptable in the urban space. Consequently, it is possible to combine the different structure of meaning.

\subsection{Conclusion from meaning theories}

The physical existence of the urban fabric is the realistic thing to start from with its existed Structure and Phenomena. The problem is that both elements have a dynamic identity and influence that has an unremitting change, this is important when the case of discussing is related to the traditional are in cities, it will be more complicated if it has some historical monuments or religious shrines. From this point of view, there is a need to understand the urban fabric through:

1-Direct involvement in the studying the urban space, this provides direct interaction with space with all its features and manipulations, it is exploring the Part of the Wholeness of the urban structure which is a real understanding for the Phenomena.

2-The study of the Relations between parts, these could be varied from different and varied structures and influences (inside/outside), (Down/Up), (Focus/Diffusion), (Toward/backward),...etc. The effects of this principle will be very evident in the case study of Erbil City.

3-Combine the different structure in such a way that each structure could be distinguishedconsciously from the whole overlapped structure in the urban Form.

Just in combining those (Figure 1) three points there will be an acceptable approach to understanding the urban form.

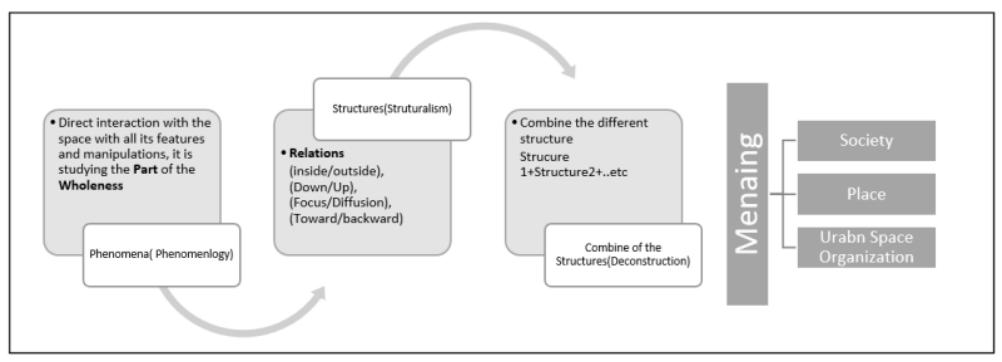

Figure 1.Methodology. Source: Developed by the Author.

\section{Traditional Urban fabric as a product of the interaction between the social, culture and the physical existence.}

Most of the values in cities located in the traditional area where the physical form and the spatial distribution of activities in the city partly contained in the traditional fabric.

\subsection{Centrality / Exteriority}

This element is more related to the whole understanding of the urban space from one side and the urban fabric as a whole phenomenon. The human being could understand the city or a part of the urban fabric when there is the point of interactions or social gravity to guide the people to those points. This principle reached its maximum in the traditional cities and historical towns and lost that importance on behalf of the Exteriority in the gridded system where space has a fluent continuous dimension. According to this element, all the direction could lead to something more important or a place where all these points collected together or leading to some other place that has more gradient power or performance. This type of movement has its own internal rules as centrality has its own morphological rules.

\subsection{Exposure / Enclosure}

Raymond Unwin declared that iwe should secure some orderly line up to which the country and town may each extend and stop definitely..) (Samuels, 2004). The principle related to the enclosure of the space and feeling of the 
human that he is in a definite way. A type of interaction between the people and building around them. Unwin (1909) confirmed the previous point by saying that « the designer of the buildings, much may be done to produce interest and variety in the street pictures, while at the same time maintaining the general sense of unity which is usually so wanting in modern suburban roads.) (Unwin, 1909). Feeling to be inside is an influential factor to encourage social activities it is thus tempting to correlate the particular morphology of the close with these types of common practice.

\subsection{Concentration/ Separation}

The mental image of cities depends on some point as landmarks to create a comprehensive mental image for the city. Lynch described it as nodes that according to him «Nodes are points, the strategic spots in a city into which an observer can enter, and which are the intensive foci to and from which he istraveling. They may be primarily junctions, places of a break in Transportation, a crossing or convergence of paths, moments of shift from one structure to anothen (Lynch, 1960).

However, it is "an outstanding feature of the visual cityscape, a marker that helps anchor the individual's mental map of the city.y (Williams, 2010). Without these landmarks or focus point, the observer loses the ability to build an image or description of the layout that he is trying to decipher. This concept changed according to the modern development and transportation requirements "Due to dynamic of urban growth the city expanded itself to the exterior part of the city" (NIA \& SULEIMAN, 2017).

\subsection{Continuity/Discontinuity}

The continuity of the space was one of the aesthetic value of the modern space, accordingly "The Aesthetic Values based on creating simple, straight Shapes and forms, the whole Compositions stand on square forms" (Amen,2017) This structure is related to the continues urban language in the traditional area, «In ordinary daily life people need more continuity and predictability in their surroundingsı (Williams, 2010). People inside any space need enough mystery and complexity to keep their interest in looking around them. Discontinuity in the language or the structure lead to misconception and fragility of the meaning, some cities suffered from this kind of discontinuity when some elements inserted which is far from the existed structure or which is in the total discord with it. That why there should be guidelines and structures assuring continuity both regarding physical form and cultural context.

\subsection{Variations/ uniformity}

The principle is related to the dynamic change of the space and place simultaneously with the movement of the pedestrian. Space focus on internal elements inside the traditional cities which are similar to the human scale and the limit of the definition of the space, these variations can drive by personality, status, and culture. Most of the traditional cities built compactly for some or other reason that reason ranged from religious, social and environmental issues and manifestations. The Variation is a reflection of two factors, the scale, and movement. The variations of the area depend on the magnitude and power of connectivity and disconnected perceptual image.

\section{Erbil City Center /Kurdistan Region/ Iraq}

Abril is ancient town, in Kurdistan Region, in the foothills of the mountains that rise to the east. Abril is one of the oldest continuously inhabited cities in the world according to the UNESCO. The current city inhabits the top of a hill formed by consecutive building over an extended period), rising about 100 feet. Ongoing efforts to revitalize the Citadel and the close relationship that the people of Erbil have will be determining factors in returning the Citadel to the role and position it has always held in its history, and as an urban landscape of importance for all humanity.

\subsection{Centrality / Exteriority}

The traditional old city concentrated on the existence of the old castle; there is no other element could contest the monumentality of that part, the language of the centrality was unambiguous where the spectator used to keep in the unconscious that there is something important to concentrate. The concept of centrality represented in the existence of the castle and the spaces and the pedestrians all around it. The idea of centrality suffered from the development when the developer decided to locate a gigantic commercial mall in opposite direction of the Citadel (Figure 2). The procedure followed the location of the new mall is a sharp contrast with the old castle, this difference enforced and increased by creating removing the area between the two ports Creating a sharp slicing with the old fabric. Here 
we find the new language stand on creating more nodes instead in the old structure node stranded on the only one prime existence.

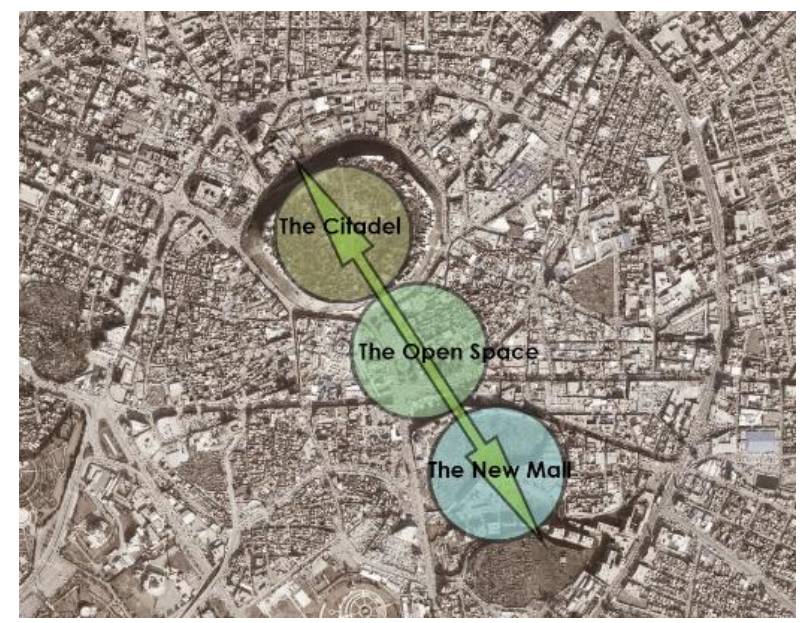

Figure 2. New Centers near the citadel pushing out Source Developed by the author.

\subsection{Exposure / Enclosure}

This structure has reversed in the center by creating the open space in the primary is that cause the changed the direction of looking from inside that was looking to the castle to outside, which is the developed Open Space. In the first case, space was secondary in position to the castle while the development made the castle walls worked as an envelope to the new space (Figure 3). The whole philosophy of the urbanform and space organization changed according to the new term.

\subsection{Concentration/ Separation}

According to this mental structure, there is a particular thing that we have to concentrate. More dominant points in the same area result in a competition between the forces and distort the internal structure of the mental images in the area; the more concentrated the points, the more distracted the people with the area. That is evident in the old city of Erbil where the Old castle which once was the focal point of the whole town lost its power in favor of the New open space built on demolishing the old fabric and the giant mall -Nishtiman Mall-( Figure 4).

\subsection{Continuity/Discontinuity.}

This principle related to the atmosphere of the space all around the citadel, there was a direct visual interaction between the citadel before the development. The continuity disrupted when the developer suggested building a barrier between the fence and the old souq, from another side the deliberate use of the brick material forced the old citadel to lose its specialty in favor of the new design. The main languages used in the new development, as well as the between the Citadel, features proposed by the new developers. The second point continuity of the space created a direct visualization with the new mall that made the Citadel work as a barrier for the newly developed open space.

\subsection{Variety / Uniformity}

The transformation from the ambiguity to uniformity in the form of new space in the central area lead to loss of the diversity of the space and make something similar to an international space in the old central area. At the same time using the same material in all around the old citadel create a feeling of repetitive with enforced rapture with the old skin.

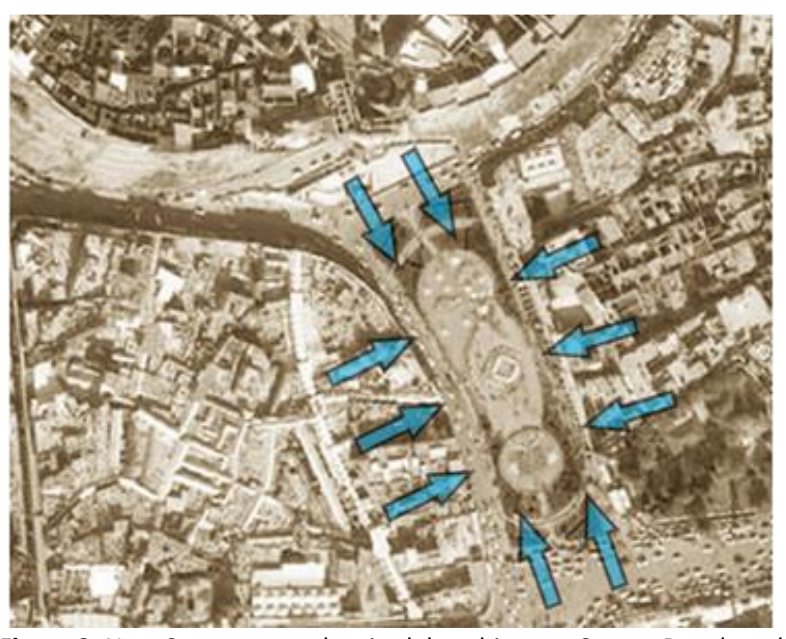

Figure 3. New Centers near the citadel pushing out Source Developed by the author. 


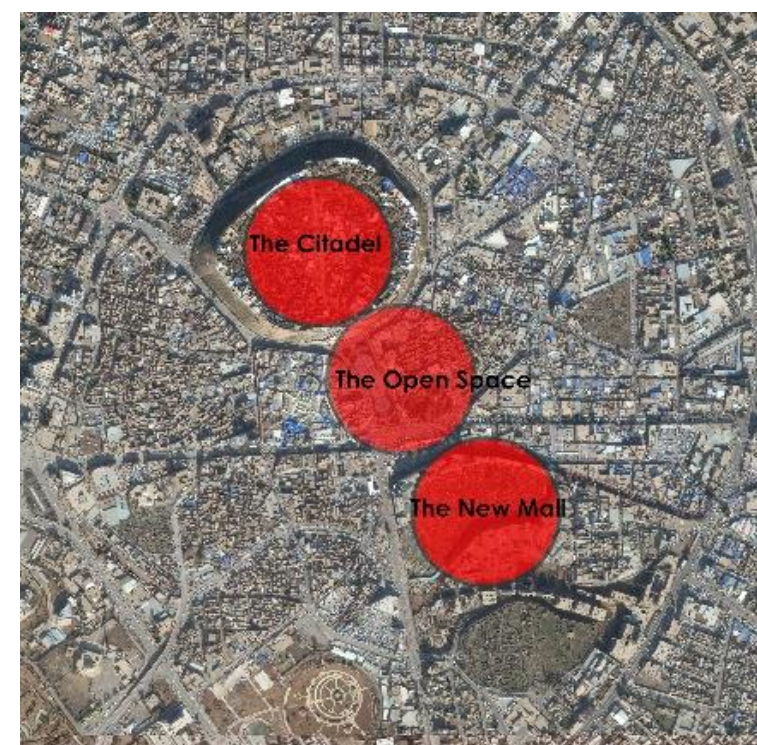

Figure 4.Both side of the new square development with sharp contrast.

\section{Al-Kadhimiya /Baghdad/Iraq}

Kadhimiya is one of the suburbs of Baghdad and its holiest place; it is $5 \mathrm{~km}$ to the north of the center of Baghdad. The urban fabric of the city organized around the sacred shrine; the municipality developed the area in 1980, the area around the main shrine demolished with roads crossing the area all the way to the main shrine (Figure5). The new project has characteristics with sharp discord with the structural view of the area. In comparison with the five fundamental points, we will find that the language is transformed according to as it cleared below.

\subsection{Centrality / Exteriority.}

Here we could conclude that the creating of the giant space all around the shrine made the shrine wall works as a barrier for space (Figure 5), which competes in power with the existence of the shrine itself. It is as two centers of authority in the same area power of shrine and the spaces all around it and competing with the first one.

\subsection{Exposure / Enclosure.}

Here the whole procedure change as space worked as a magnet to expose the entire shrine while it was enclosing it the first stage.

\subsection{Concentration/ Separation}

Almost the newly created space is diffusing the power of the old shrine.

\subsection{Continuity/Discontinuity.}

The right axis and isolation all together worked as one combination to increase the segregation with the other part of the city.

\subsection{Variety / Uniformity.}

The unique material and design of the shrine forced to sharp repetition that all these elements created in s diverse way that affected the urban fabric, and most of the solution run opposite to the old City structure.

\section{Conclusion}

The urban fabric is the final product of the prolonged process between human activities and the architectural space; each part contains a compatible structure with the other part. It is good to comprehend that many layers of meaning and transformation live implicitly in any urban fabric, that why there is a difficulty to understand the urban fabric through one layer of interpretation.

As we have seen through the paper, there was a sharp conflict in the internal structure of Erbil old city, and the developed one. The most important part of the city (the Citadel) has lost its power and gravity influence in favor of the newly developed space and the giant mall just in the opposite direction. Also, the using of traditional material around the Citadel worked to reduce the impression of the Citadel old walls and features. All these elements worked in large part to crash the old structure and create conflict with the old one and create a language based on diffusion, marginality, and exposure which in all combinations are in far contrast with enclosure, centrality, and variety that the old fabric had adopted. There is a sharp atmosphere between the existing fabric and the developed models, some new element (the new open space) has started to share the centrality with existed dominant elements (the Citadel).

Baghdad city suffered from the same differentiations and points. The approved design by the municipality focused on the negative space that decreases the dominance part of the shrine. That why any urban fabric should keep multi-layers of interpretation extracted from the diachronic period of city life that is the main point to start with to build a real image for cities that based on cultural and social activities. 


\section{Acknowledgments}

This research did not receive any specific grant from funding agencies in the public, commercial, or non-for-profit sectors.

\section{References}

Amen, M. A. (2017, August). The inspiration of Bauhaus principles on the modern housing in Cyprus. Journal of Contemporary Urban Affairs, 1(2), 21-32. https://doi.org/10.25034/ijcua.2017.3645

Hlillier, B., \& Hanson, J. (2009). The Social Logic of Space. Cambridge University Press. https://www.cambridge.org/core/books/soci al-logic-of space/6B0A078C79A74F0CC615ACD8B250A $\underline{985}$

Lawson, B. (2001). The Language of Space. Architectural Press. https://www.amazon.co.uk/LanguageSpace-Bryan-Lawson/dp/0750652462

Leach, N. (1997). Rethinking Architecture. Routledge.

https://designpracticesandparadigms.files.w ordpress.com/2013/01/leach-ed-rethinkingarchitecture.pdf

Lynch, K. (1960). The Image of The City. Cambridge, MA: The MIT Press. http://www.miguelangelmartinez.net/IMG/p df/1960_Kevin_Lynch_The Image_of_The_City book.pdf

Mallgrave , H. F., \& Goodman, D. (2011). An Introduction to Architectural Theory 1968 to the Present. Wiley-Blackwel. https://www.wiley.com/enus/An+Introduction+to+Architectural+Theory \%3A+1968+to+the+Present-p-9781405180634

Massey, D. (2008). Doreen Massey: For Space. SAGE Publications

Ltd. https://selforganizedseminar.files.wordpress.C om/2011/07/massey-for_space.pdf

NIA, H. A., \& SULEIMAN, Y. H. (2017, August). Identity in Changing Context: Factors of losing Identity in new developed part of the city of Famagusta, North Cyprus. Journal of Contemporary Urban Affairs., 1(2), 11-20. https://doi.org/10.25034/ijcua.2018.3661

Samuels, I. (2004). Urban forms the death and life of the urban block. Architectural Press. https://www.amazon.co.uk/Urban-FormsDeath-Life-Block/dp/0750656077

Schulz, C. N. (1991). Genius Loci: Toward a phenomenological view in Architecture. Rizzoli. http://home.fa.utl.pt/ al7531/pedidos/livros/ Genius\%20Loci\%20Towards\%20a\%20Phenom enology\%20of\%20Architecture.pdf

Tyson, L. (2006). Critical theory today: a userfriendly guide. New York: Routledge. https://www.amazon.com/Critical-TheoryToday-User-Friendly-Guide/dp/0415974100

Unwin, S. (1909). Town Planning in Practice: An Introduction to the Art of Designing Cities and Suburbs. : . New York: Charles Scribner \& Sons. https://trove.nla.gov.au/work/11624231

Williams, J. (2010). Understanding poststructuralism. New York: Acumen. https://www.amazon.com/Understanding-

Poststructuralism-Movements-ModernThought/dp/1844650332

Winters, E. (2007). Aesthetics and Architecture. Continuum International Group. New York: Routledge.

https://www.google.com/urle $s a=t \& r c t=j \& q=$ \&esrc $=s \&$ source $=$ web\&cd $=1$ \&cad=rja\&uact $=$ 8\&ved=2ahUKEwiE2IWCha fAhWvtYsKHQ42C 5wQFjAAegQIDBAC\&url=http\%3A\%2F\%2Faest hetics.ff.cuni.cz\%2Ffile download\%2F21 \&usg =AOVVaw1YfZc9VP2nsz64GSpkl_ZX 